Session 3253

\title{
Integrating the First Two Years of Engineering Education
}

\author{
Marc Hoit and Matthew Ohland \\ Civil Engineering, University of Florida
}

\begin{abstract}
The University of Florida (UF) is conducting an integrated engineering education experiment (covering the first two years of engineering education) for the Southeastern University and College Coalition for Engineering EDucation (SUCCEED), one of the National Science Foundation's Engineering Education Coalitions. The guiding purpose of this effort is to provide students the same benefits that have been achieved through total program integration while avoiding some major drawbacks of such schemes, such as significant changes in program administration.

We propose a model different from the total integration model, which has dominated curriculum reform research. In our model, course and department frameworks remain intact. Instead, we are changing the way faculty teach and the way students' time is structured to increase learning efficiency. We have 100 students enrolled in the program and plan to work with them for two years. Special sections of Calc I and Chemistry I were taught in the Fall semester of 1995. Sections of Calculus II, Chemistry II and Physics I are in progress during Spring 1996. These special sections are reducing the dependence on lecture and relying more on active and group learning models. More "studio" classes are being used to improve learning.
\end{abstract}

\section{Introduction}

The University of Florida (UF) is conducting an experiment to improve the first two years of engineering education. This time period in an engineer's education is referred to as Stage I. This research is supported by the Southeastern University and College Coalition for Engineering EDucation (SUCCEED), one of the National Science Foundation (NSF) engineering educational coalitions. This experiment represents one part of a larger SUCCEED project with other work being conducted at North Carolina State University (NCSU) under the leadership of Dr. Richard Felder. The UF portion consists of a radical change in the way we prepare our students for upper division engineering education. Traditionally, engineers take two years of math, chemistry, physics and humanities before entering the engineering disciplines. A number of innovative first year

experiments have been conducted during the past several years at selected schools. The Rose Hulman ${ }^{[1]}$ and 
Drexel ${ }^{[2]}$ models are excellent examples of the total integration of courses and topics to create a single freshman course. As a result of their success, most engineering curriculum reform has focused on the idea of an integrated course structure. NCSU will follow the integrated course model but concentrate on innovative teaching methods, including cooperative learning.

We propose a different model for reform. In our model, course and department frameworks remain intact. In addition, modified use of large lectures will be examined. Instead, we plan to change the way faculty teach and the way students' time is structured to increase learning efficiency. Information from other SUCCEED projects is being used to determine the knowledge structure and skill base that should be incorporated as the required content. The experiment has the following five underlying goals:

1) Provide a more structured academic and social learning environment.

2) Provide engineering applications and introduce the engineering thought process early on.

3) Search for models that are sustainable, cost effective and exportable.

4) Match teaching and learning styles (e.g. cognitive and active learning).

5) Develop an advanced learning laboratory to provide optimal physical facilities.

This project plans to expand the use of engineering applications and design into the first two years of preparatory work. Providing an education with such an emphasis is expected to attract and retain engineering students by showing applications of the math, physics and chemistry they have learned. Since this program is designed to use the existing departmental framework, it is easy to export to other schools.

Recognizing that evaluation and assessment are essential to proving the value of program implementation, we have integrated their design with the planning process as a whole. A description of assessment is included.

\section{Program Goals}

By concentrating on teaching methods and helping students structure their time more effectively, it is believed that better students and life-long learners can be developed. Students come from the high school environment where each hour of their day is planned. In college, their time is largely unstructured and unmonitored. Later, they enter the work place where their time becomes structured again. During college, where their time is less structured, is when many students have trouble. Many non-engineering professional disciplines have more structured environments. Architecture traditionally has studio classes which involve large blocks of time in active learning environments.

In upper division engineering courses, it is common to have three hour lab sections where everything from problem sessions to true lab experiments are conducted. Students tend to work in teams on assigned homework and design projects in these structured classes. During this same period, student societies and constant group interaction tend to dominate their social activities. In addition, much of the upper division engineering 
curriculum is focused and lock-step. A major goal of our program is to provide more structure in the first two years of college, when it is lacking.

A major goal of SUCCEED (and many other coalitions) is to introduce engineering content into the early terms of an engineer's education. It is proposed to do this by two methods. The first is the common method of using engineering applications as motivators for learning basic subjects. An example of this is using engineering problems like beam deflection to teach integration. The second and more important method is to introduce the engineering thought process into these early classes. Engineers use a very application-oriented, get-somethingthat-works approach to problem solving. The use of open-ended problems and teaching problem solving at early stages has shown to be beneficial to engineering students. ${ }^{[3]}$

Necessary attributes of the project are that the methods of this project must be sustainable, cost effective and exportable. To do this it is believed that the departmental nature of education must be retained. That is, separate courses taught and controlled by individual departments. The content, goals, and applications are determined through cooperation rather than complete integration. Many of the barriers that exist for subject integration are centered on content. It is also believed, for example, that mathematicians know best what math content should be included in specific courses. However, when faculty from different disciplines interact while teaching an integrated course, they see the necessity of blending the boundaries. As a result, our proposal continues to have the math department teach math classes. In addition, the departments must be free to teach these courses in their traditional single course, non-integrated format. This is not to say that topics being taught, sequence of topics, and format for delivery do not all need to be reviewed and modified. However, this modification will result in independent courses taught by different departments.

The project incorporates active and cooperative learning styles into the first two years of course work. Educational research has shown that there are many different types of learners. In typical basic courses, only one teaching method is employed -- lecture. On average, students learn better when they are active participants in the learning process. Group efforts, hands-on learning and self-directed learning are some of the many methods that encourage better learning.

Finally, the use of advanced technology is common in many engineering courses. It is not as common in the lower division courses. All of our upper division engineering courses use computers heavily. Other schools have tried integrating computer applications such as symbolic algebra programs in calculus with great success. Some universities require that entering students purchase their own computer with a common set of software tools. A complete integration of modern software tools throughout the engineering program is required.

\section{Implementation}

In order to provide a more structured academic and social learning environment, the first step was establishing a unified curriculum. The team decided that program students would take the following schedule: 
Session 3253

\begin{tabular}{|l|}
\hline Fall 1995 \\
\hline \hline Analytical Geometry and Calculus I (4 credits) \\
\hline General Chemistry I with Lab (4 credits) \\
\hline Introduction to Engineering (1 credit) \\
\hline General Education class(es) (varies) \\
\hline
\end{tabular}

Spring 1996

Analytical Geometry and Calculus II (4 credits)

General Chemistry II with Lab (4 credits)

(optional - some majors do not require)

Physics I with Calculus with Lab (4 credits)

General Education class(es) (varies)
Fall 1996

Analytical Geometry and Calculus III (4 credits)

Physics II with Calculus with Lab (4 credits)

Biology for Engineers ( 3 credits)

(optional - some majors do not require)

General Education class(es) (varies)
Spring 1997

Differential Equations (3 credits)

Engineering courses determined by major

General Education class(es) (varies)

Additional structure was provided through a number of orientation activities. These activities included student advising and problem resolution, registration assistance, and placement exam study sessions. Students also participated in a time management exercise before the start of the semester.

Early design and introduction to the engineering thought process were accomplished by the use of applicationoriented examples in the mathematics coursework and by the inclusion of Introduction to Engineering in the first semester. The Introduction to Engineering class exposes students to all undergraduate engineering programs offered at UF through hands-on experiments and design activities. ${ }^{[4]}$

The overall structure of the program is designed for sustainability and exportability. By leaving traditional departmental structures intact, implementation cost and "turf" conflicts are minimized. Another feature which helps assure sustainability is the acknowledgement that at a school the size of UF, we cannot do away with large lecture classes altogether. Instead, we recognize that large lectures can be improved and can be supplemented by smaller class size studio work. 
Since the only solution to a mismatch of teaching and learning styles is to change the teaching approach, we hosted Dr. Richard Felder and Dr. Rebecca Brent's "Effective Teaching Workshop" (a regular event at ASEE conferences). Most of the participating faculty and teaching assistants attended, with $100 \%$ of faculty teaching first semester courses present. This workshop also addresses cooperative learning techniques.

The laboratory sessions are a significant departure from standard laboratories and recitations. In the chemistry laboratory, students use the Texas Instruments TI-85 graphing calculator and its Computer-Based Laboratory $(\mathrm{CBL})$ interface to obtain and analyze real-time data from various instruments. In the Mathematics laboratory sessions, MAPLE symbolic mathematic software has been used. The work in these laboratories has been openended and cooperative.

A donation from Sun Microsystems has provided 15 workstations to establish this "Knowledge Studio." Space to establish the technology classroom has been acquired, and it should become operational sometime in Spring 1996. Funding cycles prevented us from acquiring this equipment earlier in the project. The workstations will have the MAPLE symbolic mathematic software currently used by the students as well as other application software and equipment. More than providing advanced technology for the students to use, this space is intended to establish a common space in which the students will have instruction, lab meetings, cooperative workspace and homework areas in all their subjects.

The concept of the technology classroom is an extension of what is already being used successfully in upper division classes and in art classes. Time spent in the technology classroom is a structured time where students participate in active learning sessions. A longer (two- to three-hour) time period allows for better interaction among teacher and students as well as among students. This structured time will be used to complete homework assignments and reduce out-of-class study time.

The technology classroom is fundamentally different from our current teaching environment. This classroom is intended to be a model for the future. It will include all the tools required for teaching engineers. Part of the lab will be devoted to computer stations. Each student will have a desk with a multimedia, networked computer. The professor will have a similar system with the ability to display on a large screen from any of the systems. The use of groupware products will also be investigated for educational use. Systems will all have a consistent set of software tools including World Wide Web and library access. A classroom with 25 to 30 computer seats using workstation level machines is required.

The computer stations are only a portion of the complete technology classroom. Laboratory benches with equipment required for physics, chemistry and biology experiments will also be available. These benches will be connected to data acquisition systems with access to data from any of the room's computers. General group work areas will also be integrated with large tables as a central work area. 


\section{Logistics}

Faculty were selected at the project's inception in Summer 1993. Individual courses were modified, technology was investigated and new methods were preliminarily inserted into existing courses for evaluation in Fall 1993 and Spring 1994. We selected faculty who teach each of the required courses and are willing to experiment with new teaching methods. There is one faculty member for each course that is required in math, chemistry, physics and biology. Additional faculty include someone from the college of education to advise on educational reform and handle assessment. Three additional faculty from the college of engineering to evaluate engineering content are also retained.

Program participants were recruited from a mailing list of all applicants to the University of Florida for Fall 1995 admission who indicated an interest in majoring in engineering. Of 1068 students on that list, 534 were randomly selected to receive an invitation to participate in the program. The program was designed to accommodate 120 students. Only 93 students actually entered the program. This seemed mostly due to the requirement that students were required to enter Calculus I directly from high school. Many students were unprepared and opted to take Pre-Calculus first. The proportion of students interested in engineering and yet unprepared to take calculus their first semester is apparently still a significant problem. Further research is planned to assess the extent to which this problem exists in the freshman class as a whole.

Before classes started the first semester, students were instructed to obtain free computer accounts on one of the university's systems. These accounts would be used to establish electronic mail communication with the students for feedback and dissemination of information. When it became clear that students were not using the email system to seek problem resolution, the first meeting of the semester was called. Students were at first hesitant to open discussion. Feedback was encouraged by asking questions such as, "How are your classes compared to those of students outside of the program?"

As a result of the first meeting, we learned that students in our program were spending an excessive amount of time on lab write-ups for Chemistry. We were also informed that some teaching assistants required additional training in the use of the laboratory equipment. Although the program instructors did not attend the feedback meeting (to avoid intimidation), we all met soon thereafter to complete the feedback loop. After the first meeting, students opened up and we received feedback through all lines of communication. A second meeting was called a few weeks later to form study groups of those students who had not formed groups on their own.

There was one unexpected result of promoting group interaction. The registration process was heavily influenced by study groups/partners who wanted to take their classes together during the spring semester. In order to enable and encourage this, we will allow students to register in blocks for the remaining semesters.

\section{Program Assessment}

A wide range of assessment has been planned for the extent of the program. First semester entry and exit 
surveys have already been administered to program students and other students taking Introduction to Engineering. These surveys elicit background knowledge and interest in engineering as well as confidence level in areas supporting engineering. The survey used is identical to that used in research at the University of Pittsburgh and North Carolina State University. ${ }^{[5]}$ The same groups also took the Hestenes Force Concept Inventory ${ }^{[6]}$ prior to the semester. This will be readministered after students have taken physics.

The Myers-Briggs Type Inventory was administered only to our program group late in Fall 1995 semester. The results will be explained to the students for their own education and benefit and will be compared to other findings for groups of engineering students.

In Chemistry, approximately 100 students attended the same lectures as the students in our program, but attended the traditional laboratory instruction. These students and the students in our program were given the same exams, so their exam grades and course grades can be compared. The final exam results are shown below.

\section{Chemistry Grade Distribution - Final Examination}

\begin{tabular}{|l|l|l|l|l|l|}
\hline Letter Grade & Score Range & $\begin{array}{l}\text { Experimental } \\
\text { Frequency }\end{array}$ & $\begin{array}{l}\text { Experimental } \\
\text { Percentage }\end{array}$ & $\begin{array}{l}\text { Control } \\
\text { Frequency }\end{array}$ & $\begin{array}{l}\text { Control } \\
\text { Percentage }\end{array}$ \\
\hline A & $170-200$ & 5 & 5.5 & 22 & 21.6 \\
\hline B+ & $160-169$ & 15 & 16.7 & 18 & 17.6 \\
\hline B & $150-159$ & 10 & 11.1 & 11 & 10.8 \\
\hline C+ & $140-149$ & 6 & 6.7 & 5 & 4.9 \\
\hline C & $130-139$ & 8 & 8.9 & 13 & 12.7 \\
\hline D+ & $120-129$ & 13 & 14.4 & 12 & 11.8 \\
\hline D & $110-119$ & 5 & 5.6 & 5 & 4.9 \\
\hline E & less than 110 & 28 & 31.1 & 16 & 15.7 \\
\hline
\end{tabular}

The results from the final exam were obviously disappointing to us. With over $30 \%$ of the students in our program failing the final exam, it was obvious that their grades would suffer. The semester grade results are shown below. 
Session 3253

Chemistry Grade Distribution - Semester Grades

\begin{tabular}{|l|l|l|l|l|}
\hline Letter Grade & $\begin{array}{l}\text { Experimental } \\
\text { Frequency }\end{array}$ & $\begin{array}{l}\text { Experimental } \\
\text { Percentage }\end{array}$ & $\begin{array}{l}\text { Control } \\
\text { Frequency }\end{array}$ & $\begin{array}{l}\text { Control } \\
\text { Percentage }\end{array}$ \\
\hline A & 13 & 13.8 & 35 & 30.7 \\
\hline B+ & 9 & 9.6 & 17 & 14.9 \\
\hline B & 20 & 21.3 & 14 & 12.3 \\
\hline C+ & 16 & 17.0 & 12 & 10.5 \\
\hline C & 15 & 16.0 & 11 & 9.7 \\
\hline D+ & 5 & 5.3 & 4 & 3.5 \\
\hline D & 7 & 7.5 & 4 & 3.5 \\
\hline E & 5 & 5.3 & 5 & 4.4 \\
\hline Withdrew (*) & 4 & 4.3 & 12 & 10.5 \\
\hline
\end{tabular}

In an effort to explain this negative outcome, we decided to examine the baseline ability of the two groups as measured by the SAT II Chemistry exam. This exam is used as a placement exam by the university, and the threshold for admission to General Chemistry with laboratory is 440 for tests taken before April 1995 and 480 for tests taken April 1995 and later. As part of the program, we had waived the threshold. As a result, our population was unbiased. The plot below shows that our population has the same shape as the general population, but the mean placement exam score is nearly a full standard deviation lower. 


\section{Chemistry Placement Test Score Distribution Experimental and Control Group}

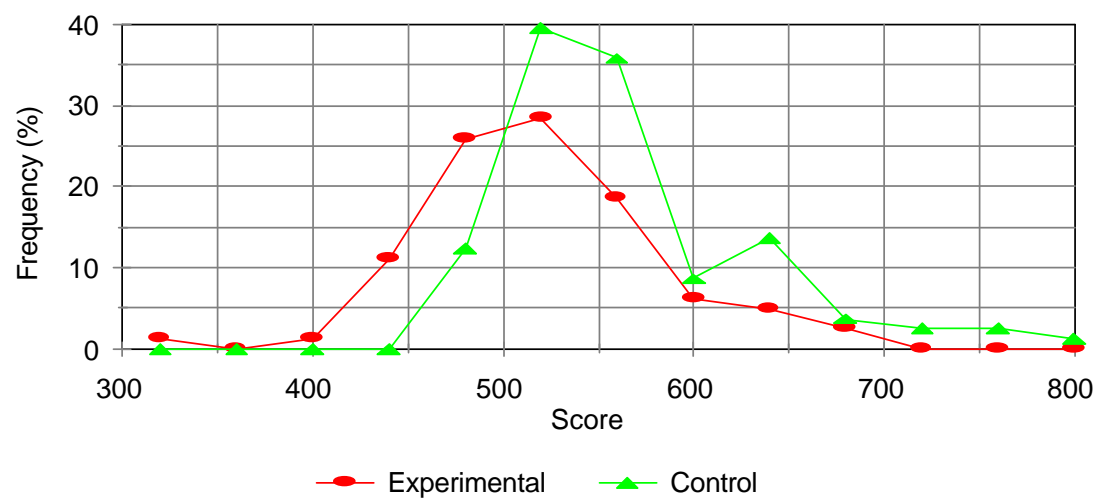

A comparison of the experimental group (those in our program) with the control group (those in the same lecture but the standard laboratory) is shown below. As illustrated by the graph, the mean placement score for our group is much lower. In spite of this, the grades for our group are approximately the same as the control group (about a $\mathrm{C}+$ ). The difference in the collective grades has no practical significance. It is also noteworthy that many more students from the control group withdrew from the course. This result is in line with the feedback we have received from students - they are working harder, but they like it, and want to stay in the program.

\section{Chemistry Placement Test Score and Course Grade Comparison Experimental vs. Control Group}

\begin{tabular}{|l|l|l|}
\hline & Experimental Group & Control Group \\
\hline Number taking Chemistry SAT II & 81 & 97 \\
\hline Mean of those taking SAT II & 505.6 & 550.3 \\
\hline Standard deviation of SAT II scores & 60.3 & 63.3 \\
\hline Number taking AP Chemistry exam & 9 & 11 \\
\hline Mean of Chemistry AP exam scores & 2.6 & 2.8 \\
\hline Number taking no placement test & 4 & 4 \\
\hline Mean of GPA (WF counts as 0) & 2.43 & 2.66 \\
\hline Standard deviation of GPA & 1.15 & 1.39 \\
\hline
\end{tabular}

An additional confounding factor was noticed, producing what is perhaps the most surprising finding to this point. 
Each data point on the plot below represents the SAT II chemistry placement score a student received and the grade achieved by the student.

\section{SAT II Chemistry Placement Exam Course grade vs. Exam Score}

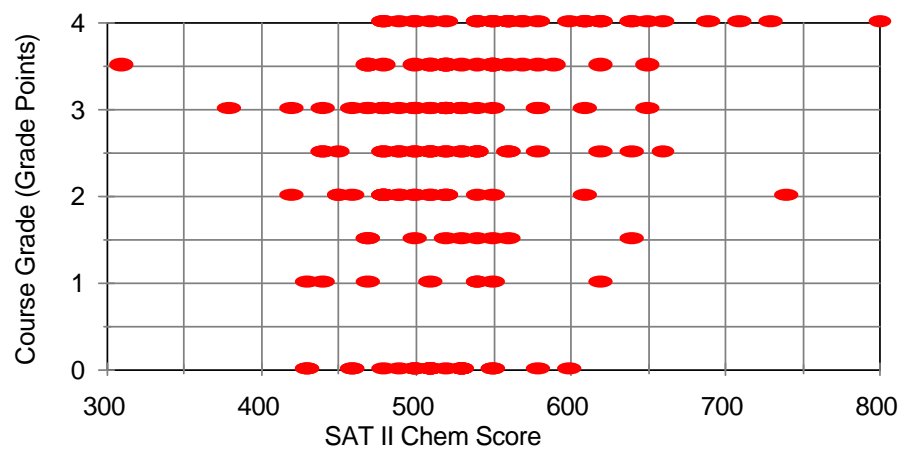

It is clear from this plot that the exam not only does not serve as a grade predictor, but does not even in this case provide adequate information to establish a threshold below which students will consistently fail the course. There are a number of likely explanations for this phenomenon. The foremost is that the exam is not necessarily taken before students have forgotten course content. Although students may score lower on the placement test because they have forgotten some material, many students will perform better when they encounter the already familiar material in the college chemistry course. We suspect that an additional confounding factor is the broad spectrum of changes which occur in a student's life at the university. Exactly what effect these changes will have on student performance is likely impossible to predict.

Since the Calculus classes in our program were completely independent from other classes, assessment would not be accomplished as simply as in the Chemistry class. It was decided that the students in our program would be given the same Calculus final exam as all other students taking Calculus I. This would allow comparison of our students to the general population on the basis of that score distribution. Unfortunately, as many of our students complained (and the scores illustrate), our students had become accustomed to the open-ended problems characteristic of their earlier exams and did not fare well on the multiple-choice, no-partial-credit exams used by the other classes. The score distributions are shown below.

\section{Calculus I Grade Distribution - Final Examination}

\begin{tabular}{|l|l|l|}
\hline & Experimental & Control \\
\hline Average (5 points per question, 105 maximum) & 61.9 & 72.1 \\
\hline Standard deviation & 25.6 & 20.6 \\
\hline
\end{tabular}


The distribution of final grades was not available at the writing of this paper, but similar results to those in the chemistry class are expected. It appears that, in this semester of transition, the students in our program do not perform significantly better or worse than the control groups. The differences between these groups should be more measurable after another semester, when retention and comprehension of previous material has more of an impact.

Data from the surveys administered at the end of the semester is not yet available. Students will also fill out surveys early in the Spring semester with specific questions about their perception of the program in which they are participating. The table below summarizes the disposition of the 95 students who began in the program.

\begin{tabular}{|l|l|}
\hline Number of students & Disposition \\
\hline 1 & Never matriculated - not counted in percentages \\
\hline 6 & Left the program and engineering for other pursuits \\
\hline 1 & Changed plan of study at parent's request \\
\hline 2 & Left engineering but are still partipating in program classes \\
\hline 1 & Transferred to another school \\
\hline 13 & $\begin{array}{l}\text { Failed Calculus or Chemistry (or both) but are making up classes } \\
\text { with the expectation of remaining in engineering }\end{array}$ \\
\hline 71 & $\begin{array}{l}\text { On track, Passed Calculus and Chemistry, Proceeded to spring } \\
\text { classes. Not all are required to take second Chemistry course. }\end{array}$ \\
\hline
\end{tabular}

\section{Conclusions}

The overall program retention rate was excellent. $89 \%$ of all students who started in the program plan to continue as engineering majors. $76 \%$ of the original program students are on track with the program curriculum. When asked informally about grade performance, students indicate that poor first semester grade performance has been due to their adjustment (or failure to adjust) to the new style of teaching and learning which is different from what they experienced in high school. Even though we are still learning how to best implement the improved teaching techniques, the students already appreciate our efforts.

The disappointment of low grade performance in Chemistry and Calculus needs to be investigated. Differences in population may account for some differences in grades. Chemistry placement exam scores for students in our program are almost a full standard deviation lower than those of the control group. The interpretation of chemistry placement scores is complicated by the fact that the scores serve neither to predict a student's course grade nor to establish a threshold below which students will likely not pass. The difference between the general population and the population of our program was permitted to occur by the relaxation of the placement exam cutoff score for students entering our program. Similar data from the general population of Calculus students is not yet available, 
but results like those observed in Chemistry are expected.

Students have indicated other less tangible benefits of the program which are difficult to assess, but are important to note. At the outset, many students were very grateful for advisement and assistance with registration. They also report that being part of a smaller group of students helped give them an identity among the almost 40,000 students at the university. Students have indicated that having an advocate in resolving class problems is a great benefit. The role of advocate has been filled primarily by the program administrators (who are not teaching any of the classes).

It is expected that the long term benefits will include improvement in grades, as students benefit from the teaching methods which encourage better comprehension and longer-term learning. These benefits should be observable in student grades as they continue on to take additional courses in Calculus and Chemistry in the Spring semester.

\section{References}

[1] Rogers, G. And Winkel, B.J., "Integrated First-Year Curriculum in Science, Engineering, and Mathematics: Nature, Evolution, and Evaluation," Proceedings ASEE Annual Conference, 1993, 186-191.

[2] Quinn, R.G. "Drexel's E4 Program: A Different Professional Experience for Engineering Students and Faculty," J. Engineering Education, 82:4 (1993), 196-202.

[3] Dally, J.W. and Zhang, G.M., “A Freshman Engineering Design Course,” J. Engineering Education, 82:2 (1993).

[4] Hoit, M.I., Ohland, M.W., "Implementing Curriculum Reform: A Case History", Proceedings 1995 Annual Conference ASEE, Anaheim, CA, June 25-28, 1995.

[5] Besterfield-Sacre, M.E., Atman, C.J., and Shuman, L., "How Freshman Attitudes Change in the First Year," Proceedings Annual Conference ASEE, Anaheim, CA, June 25-28, 1995, 157-163.

[6] Hestenes, D., "Force Concept Inventory," Physics Teacher, 30:3, March 1992, 141-158.

\section{Biographical Information}

\section{MARC HOIT}

Dr. Hoit recent contribution is a text book entitled "Computer Assisted Structural Analysis and Modeling," Prentice Hall, that integrates the use of the computer for teaching structural analysis. Dr. Hoit's research involves the analysis and design of traffic signal systems, a computer program which analyzes bridge piers, and engineering education with the SUCCEED coalition. Dr. Hoit's most recent award is the Teaching Improvement Program award in 1995.

\section{MATTHEW OHLAND}

Matthew is a doctoral student in Civil Engineering pursuing a minor in Education. His doctoral research is to create

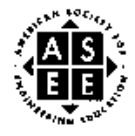


a methodology for designing engineering activities. Matthew has been recognized for his contributions to the University of Florida and its community. He plans to continue his work after graduating in August 1996. He is an active member of Tau Beta Pi and was recently nominated for Tau Beta Pi's Laureate Award. 